\title{
VOLT Valve: Applying the Frugal Innovation in a Green Touchless Low-Tech Solution
}

Ali BENMOUSSA ${ }^{1}$, Mohammed RADOUANI ${ }^{l,}$ Benaissa EL FAHIME ${ }^{l}$ and Ilyass MOUSAID ${ }^{2}$

${ }^{1}$ Department of Mechanical Engineering ENSAM Meknès, Moulay Ismail University, MEKNES, Morocco

${ }^{2}$ Technology Transfer Office (TTO) of Mohammed VI Polytechnic University (UM6P) BENGUERIR, Morocco

\begin{abstract}
In their innovative development strategy, the third world countries should escape the sheeplike behaviour by following the same pathway as the developed western countries. Because they don't have the same historical, geopolitical and social factors. There's a lot of truth behind Bruce Lee's wellknown quote: "Using no way as way; having no limitation as limitation" by using practical technique with flexibility and reliability instead of theoretical and rigid method. The Frugal Innovation is a good demonstration of this practical way with the ability to "do more with less" [1-2] by creating more business and social value while minimizing the use of diminishing resources such as water, energy and funding. Within this context, the aim of the VOLT valve, where VOLT is the abbreviation of "Valve Opening with Low Tech", is to propose an autonomous, low tech, eco-efficiency and compact product. This innovation have five distinct aspects that can be resumed in two words, WLoG NoTS (Water, Low, Green, No Touch and Social Technology) which is reflecting a homophony with " Have nots " who need to meet their energy and water needs in a quick and smart way.
\end{abstract}

\section{Introduction}

The current health crisis in India, with the explosion of new cases of coronavirus, shows us the fragility of Third World countries where, according to the International Commission of Jurists ICJ [3] "Many people in India, particularly those living in poverty, in informal settlements and rural populations, lack access to clean water. In addition to the many ordinary purposes for which access to clean water is ordinarily necessary, there is the need for frequent hand washing to protect from, and prevent the spread of, COVID19."

On the other hand, according to a clinical study conducted in Hong Kong and published in the annals of internal medicine [4], "Hand hygiene and facemasks seem to reduce influenza virus transmission when implemented early after symptom”.

In this context, finding a hand washing valve with a Touchless and low-cost solution to prevent any contamination with the frequent use of mechanical opening valve, installed in most homes, needs to be urgently addressed.

For this raison, the frugal innovation FI is the best innovation strategy for an emerging country like Morocco, in the same way that the Lean philosophy, with the Toyota Production System (TPS), was for the production strategy of car manufacturing.

As shown by the timeline diagram in the Fig.1 [5], since 2010 the developed and the emerging countries are in an equal-footing relationship due to the new globally networked innovation.

The traditional R\&D models, with their bureaucratic system, is too costly, rigid and unable to deliver an autonomous, low-cost, eco-efficiency and compact solutions for poor customers.

Frugal innovation, with an entrepreneurial mindset, is the best approach for providing such costeffectiveness, social impact and energy-efficiency. [67]

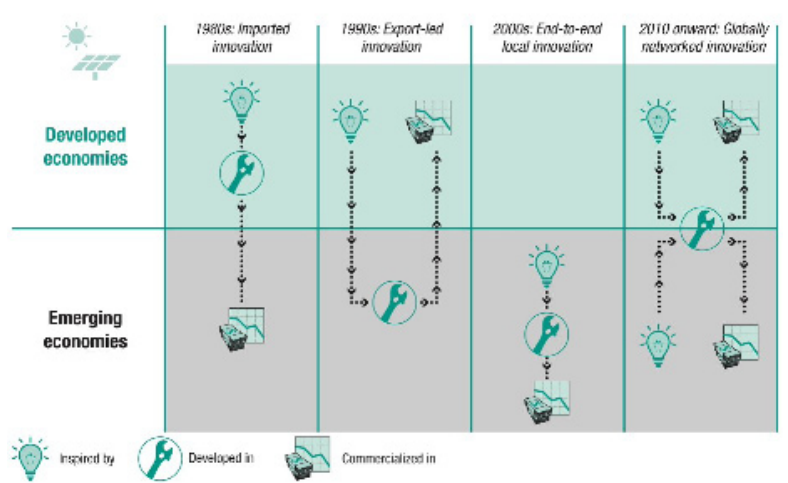

Fig. 1. The Changing Geography of Innovation [5]

As discussed in Weyrauchand \& Herstatt paper's [8] "frugal innovation mostly occur within the three main categories cost reduction, functionality, and performance level, where the difference between frugal innovation and other innovation types is that frugal innovation must meet all of the three criteria at the same time."

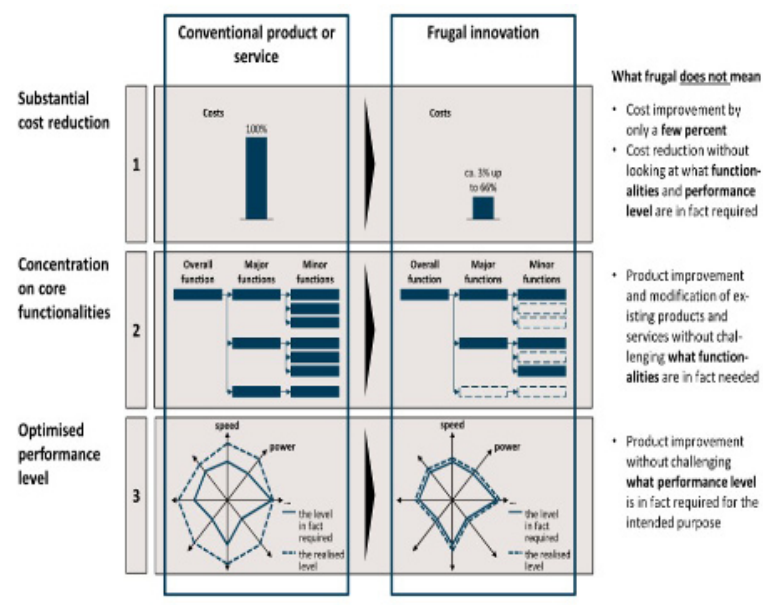

Fig. 2. Criteria for frugal innovation [8] 
For this reason, our VOLT Valve solution is an application of this innovation strategy and as a Tool Kit we will use the KTH Innovation Readiness Level with six key areas of innovation development as shown in Fig.3:

- Customer Readiness Level CRL

- Technology Readiness Level TRL: developed by the NASA during the 1970s with a scale from 1 to 9 as an indicator of the technology development and testing (Fig.4).

- $\quad$ Business Readiness Level BRL

- Intellectual Property Readiness Level IPRL

- $\quad$ Team Readiness Level TMRL

- $\quad$ Funding Readiness Level FRL

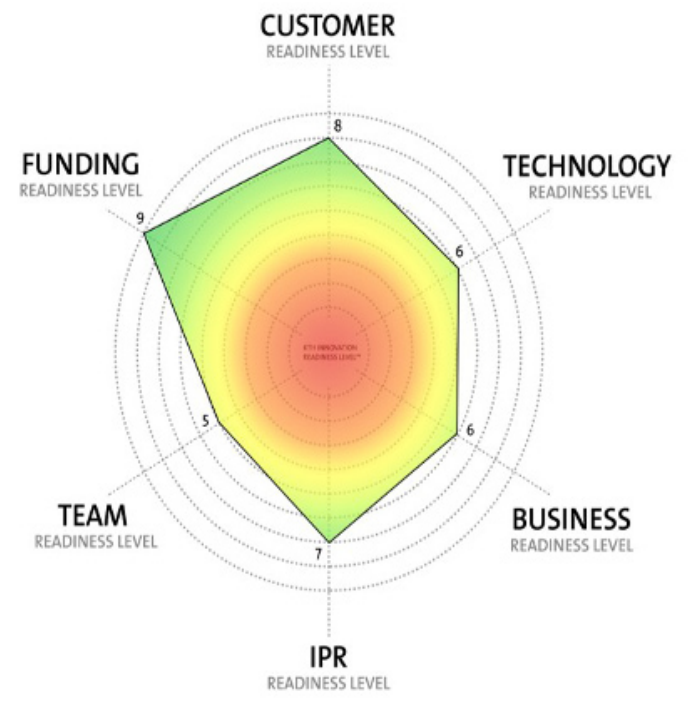

Fig. 3. KTH Innovation Readiness Level and 6 key areas of innovation [9]

The actual Technology Readiness Level (TRL) of our VOLT Valve is 4 as a technology validation in laboratory according to the figure below:

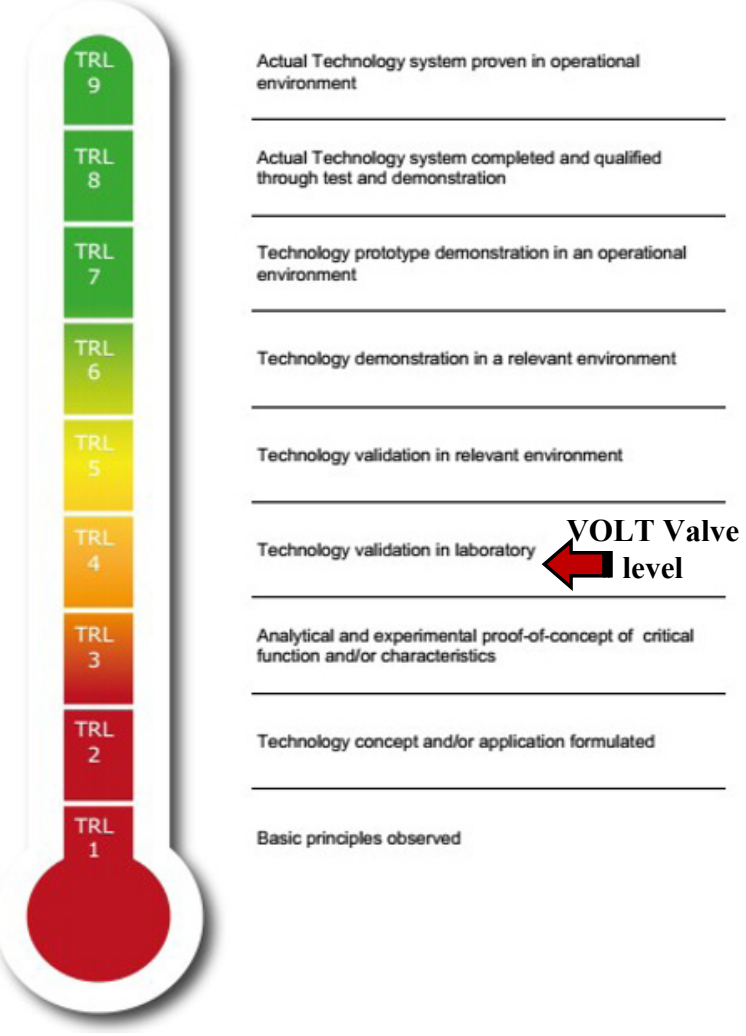

Fig. 4. KTH Technology Readiness Level indicator [9]

\section{Presentation of the VOLT Valve}

To prevent any contamination with the frequent use of a valve with mechanical opening, installed in most homes, we developed our VOLT Valve as a multifunction and compact product (MFP) with lowcost solution comparing to the total price of the three products bought separately as shown in the table 1 (nearly five time less expensive -80\%).

The main function of this solution is a valve with Touchless opening for the use of cold water, in addition to two other functions which are:

- Digital body scale

- $\quad$ Solar led with a rechargeable 5V battery.

The main idea of this innovation is to use the potential energy ,of the user's body weight, as an actuator of our valve opening instead of an electrical energy 22OV AC used in the Touchless valve with infrared sensor.

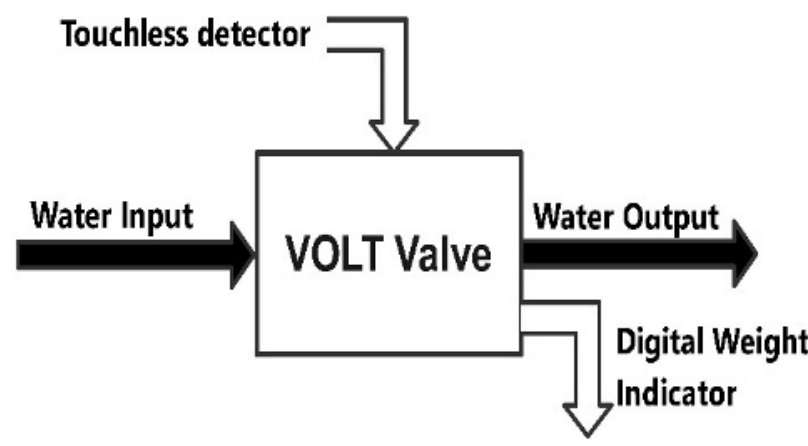

Fig. 5. Block Diagram BD of the VOLT Valve Process

Table 1. Comparison of the product Cost and energy supply

\begin{tabular}{|c|c|c|c|}
\hline \multicolumn{2}{|c|}{ Product } & $\begin{array}{l}\text { Cost in } \\
\text { Moroccan } \\
\text { Dirhams } \\
\text { MAD }\end{array}$ & Energy supply \\
\hline \multicolumn{2}{|c|}{$\begin{array}{c}\text { Our VOLT Valve with } 3 \\
\text { functions : } \\
\text { Water valve, body weight scale } \\
\text { and LED Light }\end{array}$} & 200 MAD & $\begin{array}{l}\text { No need of } \\
\text { 220V AC } \\
\text { electrical supply }\end{array}$ \\
\hline \multirow{3}{*}{$\begin{array}{c}\text { The } 3 \\
\text { products } \\
\text { bought } \\
\text { separately }\end{array}$} & $\begin{array}{c}\text { Plastic water } \\
\text { solenoid valve } \\
12 \mathrm{~V} 1 / 2 " \\
\end{array}$ & 300 MAD & \multirow{3}{*}{$\begin{array}{c}\text { Need of } \\
\text { electrical supply } \\
220 \mathrm{~V} \text { AC for } \\
\text { solenoid valve } \\
\text { and } 4,5 \mathrm{~V} \text { battery } \\
\text { for the weight } \\
\text { scale }\end{array}$} \\
\hline & $\begin{array}{l}\text { Digital Body } \\
\text { Weight Scale }\end{array}$ & 150 MAD & \\
\hline & Solar LED 50W & 300 MAD & \\
\hline & Total cost & \multicolumn{2}{|l|}{950 MAD } \\
\hline
\end{tabular}




\section{VOLT Valve Innovation Readiness Level:}

To estimate the maturity of our technology and to measure it innovation level, we will use the toolkit of the KTH University [9] (Royal Institute of Technology in Stockholm) with their Innovation Readiness Level including a scale from 1 to 9 in six key areas of innovation development.

As can be seen in the Fig. 4, our VOLT valve has a TRL of 4 as a technology validation in laboratory with a home-made prototype.

From the table of KTH Readiness level in below, we can notice the two main weak points of our innovation which are:

- The Funding need to take the idea to the market.

- The Business plan with a clear market vision.

Table 2. VOLT Valve Innovation Readiness Level

\begin{tabular}{|c|c|}
\hline KTH Indicator & Level \\
\hline $\begin{array}{c}\text { Customer Readiness Level CRL: } \\
\text { confirm customer need and interest }\end{array}$ & $\mathbf{5}$ \\
\hline $\begin{array}{c}\text { Technology Readiness Level TRL: } \\
\text { develop and test the technology, product, } \\
\text { service, or concept }\end{array}$ & $\mathbf{4}$ \\
\hline $\begin{array}{c}\text { Business Readiness Level BRL: } \\
\text { establish that the concept can be } \\
\text { financially viable and feasible }\end{array}$ & $\mathbf{3}$ \\
\hline $\begin{array}{c}\text { IPR Readiness Level IPRL: } \\
\text { clarify the legal and IP situation and } \\
\text { secure relevant IP protection }\end{array}$ & $\mathbf{4}$ \\
\hline $\begin{array}{c}\text { Team Readiness Level TMRL: } \\
\text { secure the right competencies and align } \\
\text { the team }\end{array}$ & $\mathbf{8}$ \\
\hline $\begin{array}{c}\text { Funding Readiness Level FRL: } \\
\text { secure the necessary funding to take the } \\
\text { idea to the market }\end{array}$ & $\mathbf{3}$ \\
\hline
\end{tabular}

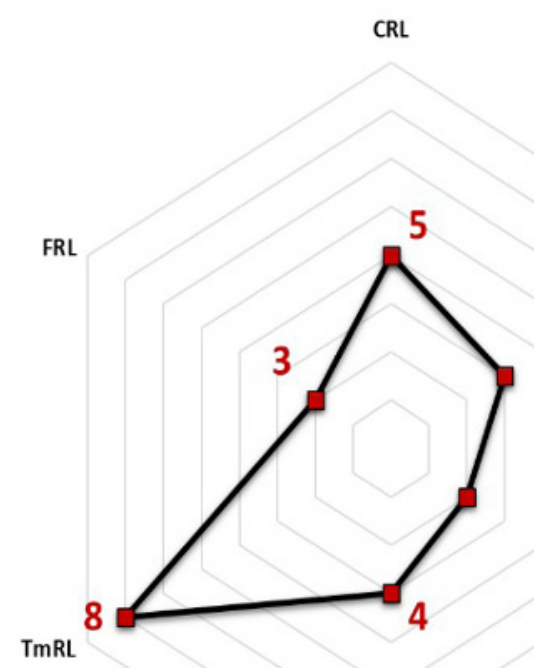

TRL

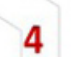

3

BRL

\section{Experimental validation of the mechanical lifting spring force:}

The main idea of our solution is to use the potential energy, of the user's body weight, as an opening force instead of an electrical energy 22OV AC used in the commercial Touchless valve with their infrared sensor.

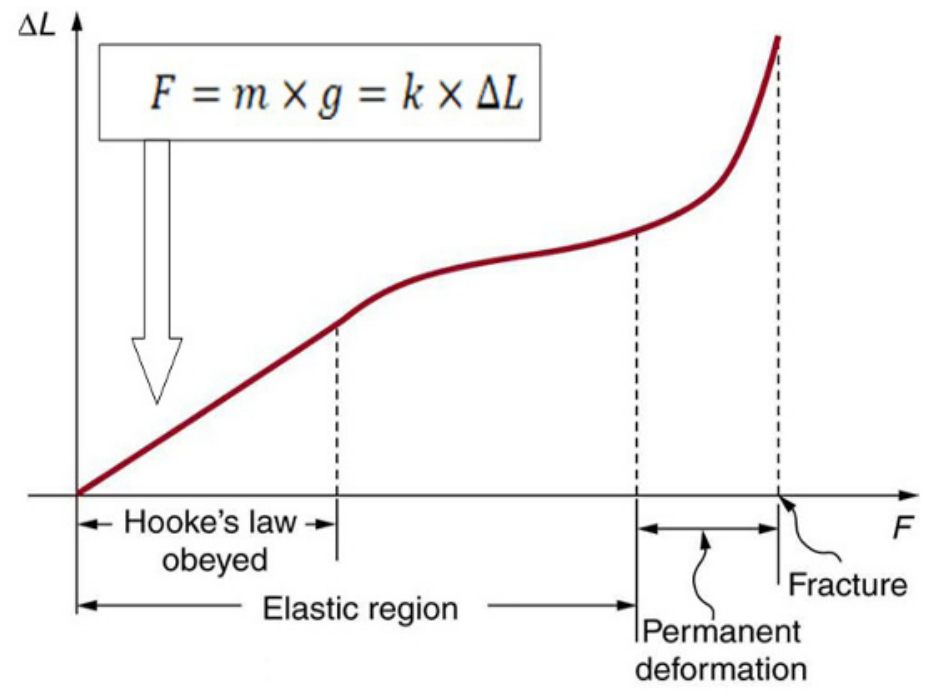

Fig. 7. A graph of deformation $\Delta \mathrm{L}$ versus applied force $\mathrm{F}$ [10]

In our experiment with home-made valve (Fig. 8 and Fig. 9), the mechanical lifting spring force is measured by changing the number of the weight plates (two kilograms) from 1 to 4 where $1=2 \mathrm{~kg}, 2=4 \mathrm{~kg}, 3=6 \mathrm{~kg}$ and $4=8 \mathrm{~kg}$ (full opening is occurred).

The $8 \mathrm{~kg}$ mass is suspended from a vertical spring such that it exerts a downwards force of magnitude 78.48 newton on the spring.

The entire lifting change length is 30 millimeters.

$$
\begin{gathered}
\Delta L=30 \mathrm{~mm}=0,03 \mathrm{~m} \\
F=m \times g=k \times \Delta L=78,48 \mathrm{~N} \\
k=\frac{F}{\Delta L}=m \times \frac{g}{\Delta L}=2616 \mathrm{~N} / \mathrm{m}[11]
\end{gathered}
$$
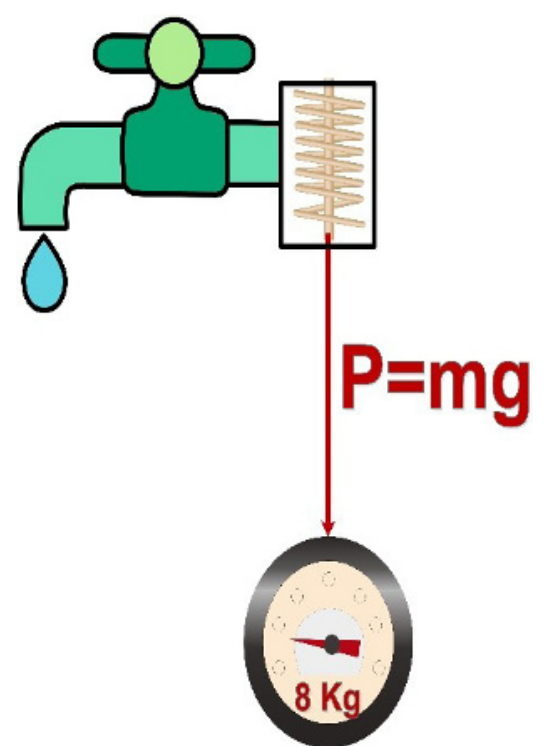

Fig. 8. The sketch of our experiment with homemade valve

Fig. 6. Radar chart of our VOLT Valve using the KTH Readiness level in six key areas of innovation development [9] 
During this experiment (Fig.9), for the mechanical spring part of the VOLT Valve with a homemade valve pulled by 4 two kilograms weight plates $(8 \mathrm{~kg})$, we validated our Proof of Concept POC step corresponding to the third level of the Technology Readiness Level TRL (Fig.4)

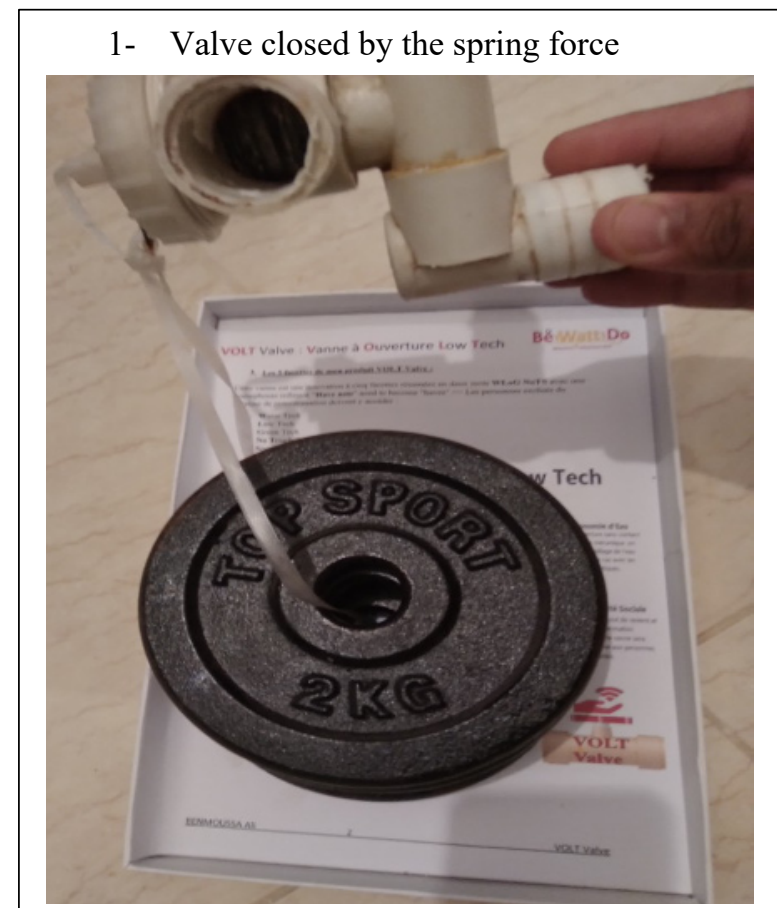

2- Valve opened by the $8 \mathrm{~kg}$ weight plates

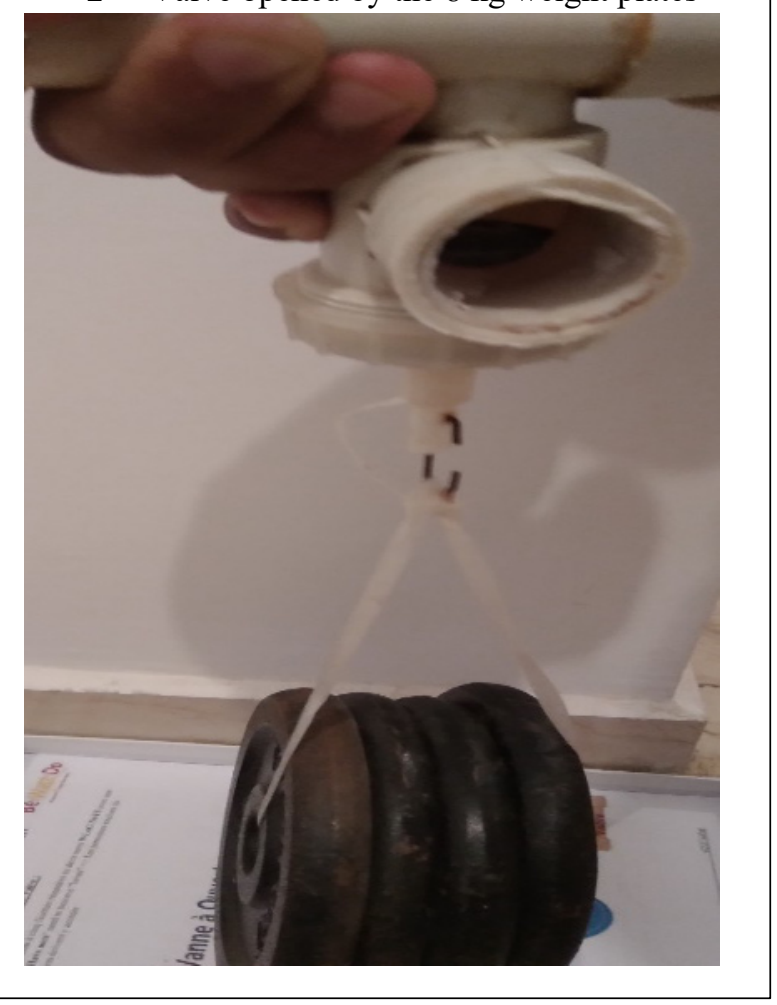

Fig. 9.Pictures of our experiment with homemade valve

\section{Conclusion :}

Despite the number of measures to prevent the spread of Covid-19, hand washing remains the most effective and basic measure.

Based on the frugal innovation approach, with the ability to "do more with less", we propose a water hand washing solution with high cost-effectiveness, social impact and energy-efficiency.

This solution with a Touchless and low-cost valve is the best alternative, mainly for the Bottom of the Pyramid BoP population [12], to the expensive touchless with infrared sensor sold in the market.

During this Proof of Concept (POC) ,which is presented as the 'critical step' in the innovation process [13] , we made a DIY prototype (Fig.9) with a cost less than 200 Moroccan Dirhams ( 20 US\$).

The next step is to have a TRL 6 with an ergonomic and an attractive design of the VOLT Valve by using our 3D printer, recently received, ANYCUBIC Photon S.

This 3D printer uses resin or Stereolithography (SLA) printing technology, also called photo polymerization [14], to create accurate and precise components for a volume less than $115 \times 65 \times 155 \mathrm{~mm}$.

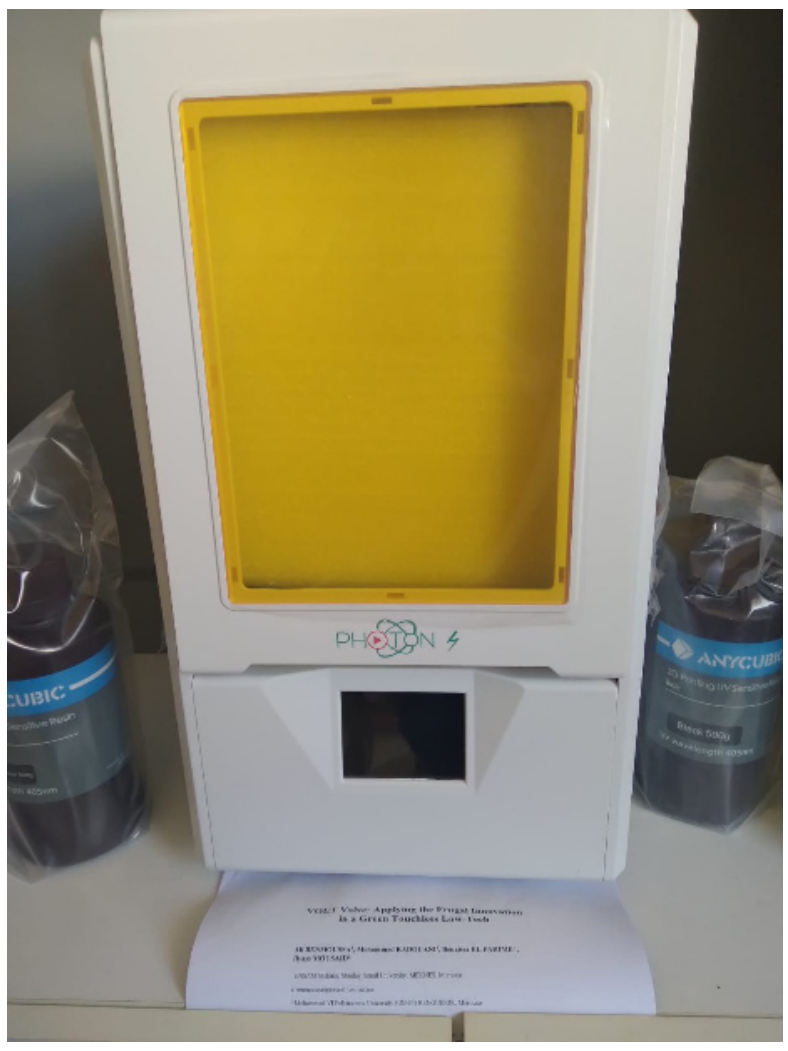

Fig. 10. Picture of our 3D printer for prototyping the VOLT valve. 


\section{References}

1. N.Radjou, J.Prabhu, S .Ahuja, Jugaad Innovation Think Frugal, Be Flexible, Generate Breakthrough Growth (2012)

2. E.Westacott, the wisdom of frugality Why Less Is More, More or Less (2016)

3. R. Goldman, FE. Marshall, COVID-19 Pandemic in India: The Right to Water, A Briefing Paper (2020): https:/www.icj.org/wp-content/uploads/2020/06/I ndia-Right-to-Water-COVID-19-Briefing-Paper2020-ENG.pdf

4. J. Cowling, H.Chan, J. Fang, Y Cheng Facemasks and Hand hygiene to prevent influenza transmission in households (2009)

5. N. Radjou, The Changing Geography of Innovation (2014) : http://regardssurlaterre.com/en/node/19807

6. M. Hossain, the frugal innovation: Conception, development, diffusion, and outcome. (2020) https://doi.org/10.1016/j.jclepro.2020.121456

7. M. Imhof, J. Mahr, Applying Frugal Innovation to Serve the Bottom of the Pyramid in Germany, Umea School of Business and Economics. (2017) Microsoft Word - Applying Frugal Innovation to Serve the Bottom of the Pyramid in Germany.docx (diva-portal.org)

8. T. Weyrauch, C. Herstatt, What is frugal innovation? Three defining criteria. (2016) DOI 10.1186/s40669-016-0005-y

9. CKTH Innovation - licensed under Creative Commons-license : CC BY-NC-SA 4.0 kthinnovationreadinesslevel.com

10. chapter 4 section 4.2 Hooke's Law: $x$-Douglas College Physics 1107 Fall 2019 Custom Textbook: https://pressbooks.bccampus.ca/ introductorygeneralphysics 1phys 1107/chapter/4-2hookes-law-originally-section-5-3-elasticitystress-and-strain/

11. PhET Interactive Simulations website : https://phet.colorado.edu/sims/html/hookes-law/ latest/hookes-law en.html

12. F. Subhan, A. Khattak, What Constitutes the Bottom of the Pyramid (BOP) Market? (2017)

13. C. Jobin, S. Hooge, P. Le Masson, What does the proof-of-concept (POC) really prove? A historical perspective and a cross-domain analytical study

What does the proof-of-concept (POC) really prove? A historical perspective and a crossdomain analytical study (archives-ouvertes. fr)

14. Guide to Stereolithography (SLA) 3D Printing Stereolithography (SLA) 3D Printing Guide (formlabs.com) 